Article

\title{
A Comparative Estimation of Maize Leaf Water Content Using Machine Learning Techniques and Unmanned Aerial Vehicle (UAV)-Based Proximal and Remotely Sensed Data
}

\author{
Helen S. Ndlovu ${ }^{1, *}$, John Odindi ${ }^{1}$, Mbulisi Sibanda ${ }^{2}{ }^{\mathbb{D}}$, Onisimo Mutanga ${ }^{1}{ }^{\oplus}$, Alistair Clulow ${ }^{3}$, \\ Vimbayi G. P. Chimonyo ${ }^{4,5}\left(\mathbb{D}\right.$ and Tafadzwanashe Mabhaudhi ${ }^{4}(\mathbb{D}$ \\ 1 Discipline of Geography and Environmental Science, School of Agricultural Earth and Environmental \\ Sciences, University of KwaZulu-Natal, Scottsville, Pietermaritzburg 3209, South Africa; \\ odindi@ukzn.ac.za (J.O.); mutangaO@ukzn.ac.za (O.M.) \\ 2 Department of Geography, Environmental Studies \& Tourism, Faculty of Arts, \\ University of the Western Cape, Bellville, Cape Town 7535, South Africa; msibanda@uwc.ac.za \\ 3 Discipline of Agrometeorology, School of Agricultural, Earth and Environmental Sciences, \\ University of KwaZulu-Natal, Scottsville, Pietermaritzburg 3209, South Africa; Clulowa@ukzn.ac.za \\ 4 Centre for Transformative Agricultural and Food Systems, School of Agricultural, \\ Earth and Environmental Sciences, University of KwaZulu-Natal (UKZN), Scottsville, \\ Pietermaritzburg 3209, South Africa; chimonyov@ukzn.ac.za (V.G.P.C.); mabhaudhi@ukzn.ac.za (T.M.) \\ 5 International Maize and Wheat Improvement Center (CIMMYT)-Zimbabwe, Mt Pleasant, \\ Harare P.O. Box MP 163, Zimbabwe \\ check for \\ updates \\ * Correspondence: 216016417@stu.ukzn.ac.za
}

Citation: Ndlovu, H.S.; Odindi, J.; Sibanda, M.; Mutanga, O.; Clulow, A.; Chimonyo, V.G.P.; Mabhaudhi, T. A Comparative Estimation of Maize Leaf Water Content Using Machine Learning Techniques and Unmanned Aerial Vehicle (UAV)-Based Proximal and Remotely Sensed Data. Remote Sens. 2021, 13, 4091. https://doi.org/ $10.3390 /$ rs13204091

Academic Editor:

Michael Schirrmann

Received: 26 August 2021

Accepted: 6 October 2021

Published: 13 October 2021

Publisher's Note: MDPI stays neutral with regard to jurisdictional claims in published maps and institutional affiliations.

Copyright: (c) 2021 by the authors Licensee MDPI, Basel, Switzerland. This article is an open access article distributed under the terms and conditions of the Creative Commons Attribution (CC BY) license (https:// creativecommons.org/licenses/by/ $4.0 /)$.
Abstract: Determining maize water content variability is necessary for crop monitoring and in developing early warning systems to optimise agricultural production in smallholder farms. However, spatially explicit information on maize water content, particularly in Southern Africa, remains elementary due to the shortage of efficient and affordable primary sources of suitable spatial data at a local scale. Unmanned Aerial Vehicles (UAVs), equipped with light-weight multispectral sensors, provide spatially explicit, near-real-time information for determining the maize crop water status at farm scale. Therefore, this study evaluated the utility of UAV-derived multispectral imagery and machine learning techniques in estimating maize leaf water indicators: equivalent water thickness (EWT), fuel moisture content (FMC), and specific leaf area (SLA). The results illustrated that both NIR and red-edge derived spectral variables were critical in characterising the maize water indicators on smallholder farms. Furthermore, the best models for estimating EWT, FMC, and SLA were derived from the random forest regression (RFR) algorithm with an rRMSE of $3.13 \%, 1 \%$, and 3.48\%, respectively. Additionally, EWT and FMC yielded the highest predictive performance and were the most optimal indicators of maize leaf water content. The findings are critical towards developing a robust and spatially explicit monitoring framework of maize water status and serve as a proxy of crop health and the overall productivity of smallholder maize farms.

Keywords: precision agriculture; maize monitoring; UAV applications; smallholder farming; machine learning

\section{Introduction}

Water stress is one of the most drastic limiting factors of maize crop production [1]. Maize (Zea mays L.) is mostly grown under rain-fed conditions and consumed by the majority of the inhabitants in Southern Africa as a staple food [2]. Due to high population growth and the increase in food and nutrition insecurities, smallholder farmers now play a critical role in maize production and in fostering food security, particularly in developing nations such as those in South Africa [3,4]. Despite their key role, smallholder farms are constantly facing the challenge of intermittent water stress and drought, resulting in 
significant yield losses [5]. More so when stress occurs from the pre-flowering to the late grain-filling stages as it is often difficult to detect the onset and magnitude of intermittent water stress [6]. In addition, spatial and temporal crop management, cultivar selection, soil, and topography affect its extent and impacts on maize yield [6]. As such, there are no clear-cut spatially explicit methods of quantifying water stress near real time in smallholder farms of the global south with limited resources. It is therefore imperative to develop optimal methods for quantifying maize water stress in a spatially explicit manner. This provides a key pathway towards effectively monitoring drought impacts and deriving useful information that can be used to inform irrigation decisions.

When maize crops are in a state of water deficit, there is a decrease in leaf photosynthesis, stomatal conductance, and leaf expansion and transpiration, subsequently resulting in impaired growth [7]. The lack of water molecules results in the loss of turgor-driven cell expansion and the primary productivity of maize crops as this has detrimental impacts on its growth $[8,9]$. Crop water deficits result in a decline in the quantity and quality of maize produce [10]. Water stress considerably affects the phenotype, reproductive system, and seed set [10]. Strong and positive correlations have been observed between grain yield and leaf water content $[7,10]$. Therefore, knowledge on the accurate estimation of maize leaf water content is necessary for crop monitoring and in developing early warning systems to optimise agricultural production in exclusively rain-fed smallholder farms [11,12].

A variety of physiological indicators have been developed to quantify crop water content as a proxy for crop water stress. They include equivalent water thickness (EWT), fuel moisture content (FMC), and specific leaf area (SLA) [13-15]. EWT is the ratio between a crop's leaf area and the quantity of water per unit area [16]. EWT is an improvement of dry matter content as it takes into account the thickness and area covered by the canopy. FMC represents the quantity of water per unit mass of leaf dry matter. It is an effective indicator of water stress or drought conditions and is commonly used in wildfire monitoring [9]. SLA is the ratio of leaf area per unit of dry mass [17]. SLA is a fundamental indicator of crop physiology and the variability of a crop's photosynthetic capacity and growth rate [18]. Although there have been various studies conducted in monitoring crop water status [7,15], there is still a disagreement on the best-suited indicator for maize water content prediction at the leaf level in small fields.

Previously, variations in crop water status were measured through conventional methods such as the visual assessment or in situ measurements conducted by trained experts [9]. However, such techniques are laborious, costly, and comparatively time-consuming, hence not feasible for continuous and time-efficient crop monitoring [19]. Over the decades, the use of satellite-borne earth observation technologies has proven to be effective in monitoring plant water status, variations in the physiology of water-stressed vegetation, and in indicating crop water requirements for improved irrigation efficiency [20]. For instance, $\mathrm{Xu}$, et al. [21] used multispectral data derived from Landsat OLI and MODIS datasets to quantify crop water content with an optimal $\mathrm{R}^{2}$ of 0.78 . Additionally, Sibanda, Onisimo, Dube and Mabhaudhi [20] utilised Sentinel-2 MSI to estimate canopy water content using EWT and FMC to an rRMSE of $20.8 \%$ and $18.45 \%$, respectively, while Krishna, et al. [22] used the combination of hyperspectral sensors and partial least squares regression to estimate rice crop water stress with an $\mathrm{R}^{2}$ of 0.94 . However, despite these successes, the application of satellite data in characterising water indicators at farm scale is restricted by their relatively coarser spatial and temporal resolutions [23]. Although there are sensors that provide very-high-resolution (VHR) remotely sensed data, such as QuickBird and Worldview imagery, these are often costly and not ideal for monitoring maize water content in necessitous smallholder farms [9].

In recent years, unmanned aerial vehicles (UAVs), commonly known as drones, have received increased attention in precision agriculture [24]. UAVs, mounted with lightweight multispectral sensors have the capacity to provide spatially explicit near-real-time information for the monitoring of crop water content [23]. Additionally, UAV proximal sensors with a sub-metre resolution deliver rapid, cost-effective, and accurate measurements 
required for the detection of the maize water status at a plot level [9]. Compared with satellite imagery, UAV-based sensors can provide datasets with exceptionally high spatial and temporal resolutions. In addition, UAV platforms can hover over a specific area of interest and can acquire imagery at lower altitudes, allowing for a finer ground sampling distance, hence being suitable for better quantification of maize water content at a field scale [9]. Various studies have utilised UAV-based proximal sensing in environmental applications [25-27]. For example, Han, et al. [28] used a DJI Spreading Wings UAV mounted with an RGB camera to estimate the plant height of maize crops and attained an RMSE of $14.1 \mathrm{~cm}$. Zhang, Basso, Price, Putman and Shuai [27] utilised a Phantom 3 UAV-based RGB image to investigate the optimal flight height for the discrimination of maize varieties. Additionally, studies have demonstrated the utility of UAV remote sensing approaches in maize yield prediction [29], maize pest and disease detection [25], and crop physiology monitoring [26]. However, these studies were conducted in controlled experimental plots in the global north. Very few studies have been conducted in the global south, particularly in smallholder croplands with rain-fed maize and other crops. As a result, the potential application of UAVs equipped with high-resolution sensors for monitoring crop dynamics such as maize water content needs to be further investigated, especially in the small, fragmented croplands of Southern Africa.

The prediction of maize water content using proximal remote sensing approaches is based on the reflectance behaviour of water molecules and dry vegetation matter in the near-infrared (NIR) and the shortwave infrared (SWIR) sections of the electromagnetic spectrum [26]. However, much of the available drone sensors that have been widely used in assessing crop water content and health have either covered the visible section of the electromagnetic spectrum or included the NIR. Very few of these studies have assessed the utility of drone sensors covering the red edge, the NIR, and the thermal sections of the electromagnetic spectrum in characterising crop water content. Furthermore, a large and growing body of literature has demonstrated the optimal performance of vegetation indices (VIs) derived from the water-sensitive sections of the electromagnetic spectrum as an instrument for retrieving crop water status [7,8,30]. For example, the Normalised Difference Water Index (NDWI), Normalised Difference Vegetation Index (NDVI), Green Chlorophyll Index (CIgreen), and the Red-Edge Chlorophyll Index (CIrededge) have demonstrated significant correlations with crop water indicators [12,30]. It is in this regard that the combination of the drone-derived red-edge, NIR, and thermal bands in conjunction with optimal vegetation indices were anticipated to yield accurate estimations of maize water content in smallholder farms.

A range of regression techniques has been proposed for the prediction of vegetation parameters using remotely sensed data. These may be broadly categorised into two: conventional regression methods and machine learning techniques [31]. A major limitation of conventional techniques, such as linear regression (MLR), is that they assume an explicit relationship between measured biophysical parameters and spectral observations, thus limiting their applicability to spatially complex datasets [32]. Recently, machine learning regression techniques such as support vector machines (SVM), random forest (RF), artificial neural network (ANN), partial least squares (PLS), and decision trees (DT) have gained popularity for their high performance in computing, quantifying, and understanding complex processes in agricultural applications [33]. Jin, et al. [34], for instance, applied the SVM model to estimate the leaf water content of maiden grass and achieved an exceptional model accuracy $\left(R^{2}=0.98\right)$. Sibanda et al. [20]_ENREF_24 implemented the RF ensemble to predict the canopy water content of grasslands, obtaining an $\mathrm{R}^{2}$ of 0.98 and RMSE of $9.8 \mathrm{gm}^{-2}$, while Yue, Feng, Jin, Yuan, Li, Zhou, Yang and Tian [19] applied machine learning techniques, including DT, PLS, and ANN, in estimating the above-ground biomass of winter wheat. The studies above illustrate the robustness and prediction capabilities associated with machine learning regression ensembles based on remotely sensed data. Although there are other algorithms that have been used in remote sensing applications, a large and growing body of literature shows that SVM, RF, ANN, PLS, and DT are the most 
widely adopted. This is attributed to their ease of implementation, robustness especially in dealing with small sample sizes, optimal feature selection abilities as well as the high accuracies they yield. However, the literature indicates that there is no specific algorithm that is suited for a specific context. There is, therefore, a need to assess and identify the most efficient algorithm that could accurately estimate maize foliar water content using UAV-derived data in the context of smallholder croplands.

In this regard, this study sought to investigate the potential of UAV-derived multispectral imagery and machine learning techniques in the remote estimation of maize water content from smallholder croplands. The main objectives of this study were to conduct a comparative analysis in order to (1) evaluate the performance of five regression techniques in predicting maize water content, and (2) determine the most suitable indicator of smallholder maize water content variability based on multispectral UAV data. The anticipated results will help provide a technical approach for the quick and accurate monitoring of changes in either EWT, FMC, or SLA as a result of water variability in order to inform irrigation decisions and the planning of smallholder maize crops.

\section{Materials and Methods}

\subsection{Description of the Study Area}

This study was conducted at Swayimane ( $\left.29^{\circ} 52^{\prime} \mathrm{S}, 30^{\circ} 69^{\prime} \mathrm{E}\right)$, a communal area located within the uMshwathi Municipality, northeast of the city of Pietermaritzburg in South Africa (Figure 1). Swayimane is situated within the moist midlands mistbelt bioresource area, characterised by an average temperature ranging between $11.8^{\circ} \mathrm{C}$ and $24^{\circ} \mathrm{C}$, and a mean annual temperature of $17^{\circ} \mathrm{C}$. The climate in the area is relatively hot with wet/cool summers and dry winters. The area receives an annual rainfall that varies between 600 and $1100 \mathrm{~mm}$. Swayimane experienced an average air temperature of $23.94{ }^{\circ} \mathrm{C}$ and an average rainfall of $86.56 \mathrm{~mm}$ during the maize growing season of 2020-2021 (Table 1). Swayimane is distinguished by arable clay loam soils and is ranked within the top $2 \%$ of high-potential land in South Africa. Such environmental conditions support the production of various grain and legume crops. Common crops produced within the study area are beans, sweet potato, sugarcane, spinach, and maize. Swayimane is dominated by smallholder maize farms cultivated by the local community. Maize farmers in the area depend primarily on traditional methods of farming such as the use of manual labour and livestock manure for fertilizer. Maize in Swayimane is cultivated both at a subsistence scale and for additional income generation. Moreover, Swayimane is a good example of a rural setup where organic farming is conducted on a semi-subsistence scale. This highlights the success of utilising organic farming methods for the optimisation of maize yield at a minimal cost. Maize experimental plots were cultivated in summer, which is the optimal maize growing season. The maize plot covered a spatial extent of $250 \mathrm{~m}^{2}$ and was primarily rain-fed. The maize crop was sown in mid-November 2020. At the time the project commenced, the crop was 86 days old, termed the reproductive phase of the growth cycle. Specifically, the maize seedlings were at an intermediate between the kernel blister stage (growth stage R2) and the kernel milk stage (growth stage R3). This stage was selected because the literature confirms that the early reproductive stages of maize are the most sensitive to water deficits $[35,36]$. 


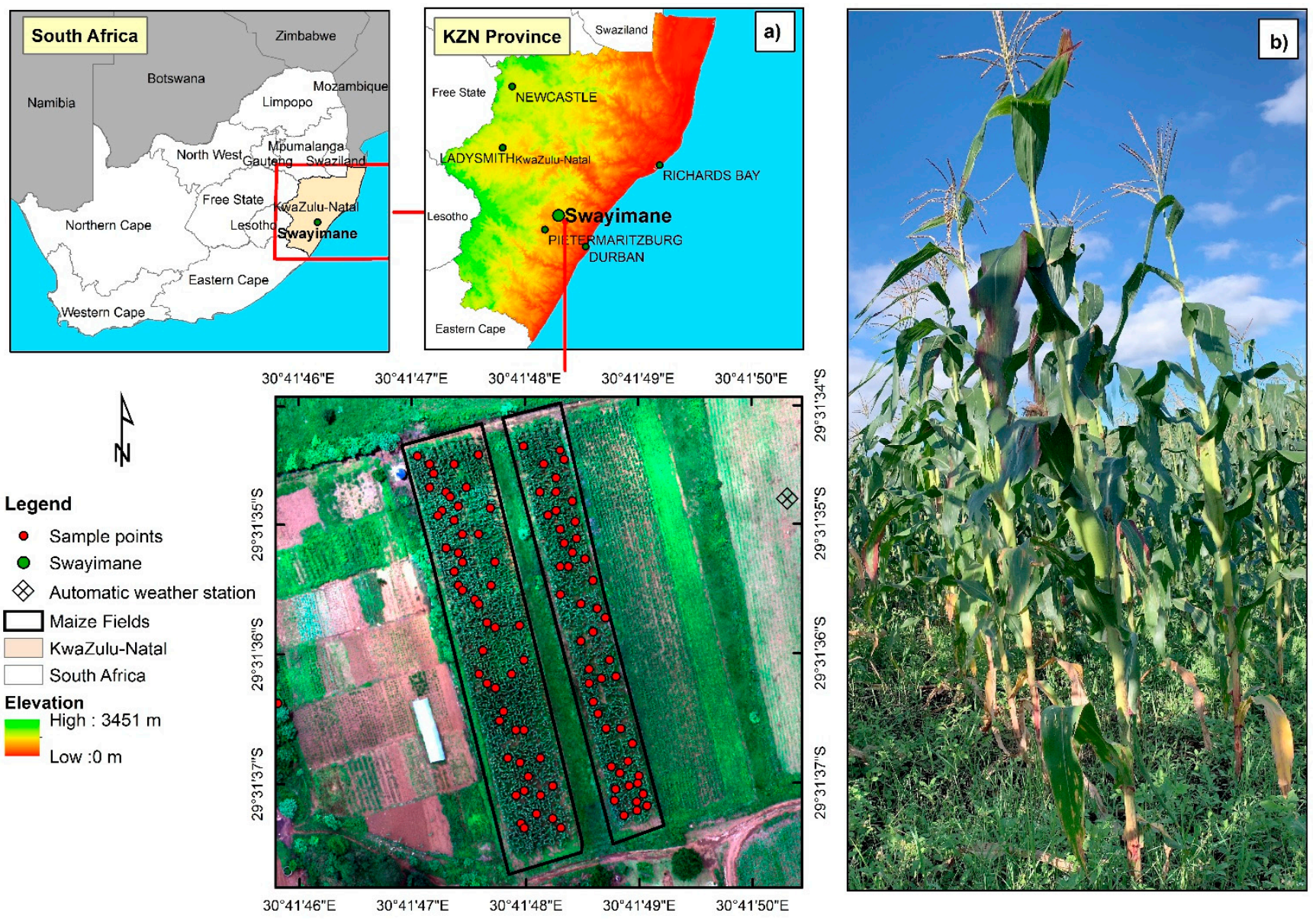

Figure 1. (a) Location of the study area and (b) maize crop field in Swayimane, South Africa.

Table 1. Bioclimatic conditions of Swayimane during the maize growing season.

\begin{tabular}{cc}
\hline Bioclimatic Variable & Data \\
\hline Average rainfall & $86.56 \mathrm{~mm}$ \\
Average air temperature & $23.94{ }^{\circ} \mathrm{C}$ \\
Average wind speed & $1.68 \mathrm{~m} / \mathrm{s}$ \\
Average vapour pressure & $2.55 \mathrm{kPa}$ \\
Average atmospheric pressure & $917.64 \mathrm{mbar}$ \\
\hline
\end{tabular}

Source: On-site automatic weather station.

\subsection{Field Sampling and Water Content Measurements}

Field data collection was conducted on 11 February 2021 at the study site. An automatic weather station (AWS) was installed in proximity to the maize fields to acquire the bioclimatic data of the maize crops. The AWS measured air temperature, relative humidity, and wind speed. Wind direction sensors and a rain gauge measured the daily wind direction and rainfall within the experimental plot. A stratified random sampling approach was used to generate a total of 104 random sample points within the maize field. This technique was selected as it could provide a representative sample of the study area. A Trimble handheld Global Positioning System (GPS) with a sub-metre accuracy was used to navigate to the randomly generated sample points within the field. Sampling fully developed leaves from the top of the maize canopy ensures reliable measurements of plant physiological characteristics, especially since these leaves receive direct sunlight and have maximum spectral reflectance [37]. The sampling of young emerging leaves was deemed not suitable for plant analysis as it could exacerbate plant stress leading to plant mortality [38,39]. In this regard, the first fully developed leaf (first leaf below whorl) was collected from the top 
of the maize canopy to measure leaf water content indicators. A LI-3000C Portable Area Meter combined with an LI-3050C Transparent Belt Conveyer Accessory with a one-mm ${ }^{2}$ resolution was used to measure the leaf area (A) of sampled maize leaves (Li-Cor, USA). The fresh weight (FW) of sampled maize leaves were obtained using a calibrated scale with a $0.5 \mathrm{~g}$ measurement error. Field measurements were conducted between 12:00 noon and 14:00 as this is the most optimal period of the day for crop photosynthetic activity [40]. The sampled maize leaves were then dried in an oven at $70^{\circ} \mathrm{C}$ until a constant dry weight (DW) was reached (approximately $48 \mathrm{~h}$ ). The A, FW, and DW were then used as input variables to compute maize leaf water indicators using the following equations:

$$
\text { EWTleaf }=\frac{F W-D W}{A}
$$

Units: $\mathrm{gm}^{2}$

$$
\text { FMCleaf }=\frac{F W-D W}{D W} \times 100
$$

Units: \%

$$
\text { SLAleaf }=\frac{A}{D W}
$$

Units: $\mathrm{g}^{-1} \mathrm{~m}^{2}$

The computed data for each crop water indicator was integrated with the GPS location and converted into a point map that was overlaid with the UAV multispectral images of the study area.

\subsection{The UAV Platform, Image Acquisition, and Processing}

The DJI Matrice 300 series (M300) and the MicaSense Altum imaging sensors were used to acquire images covering the maize field considered in this study (Figure 2a). The M300 UAV specifications are further detailed in Table 2. The Altum camera integrates a radiometrically calibrated thermal sensor with five spectral channels that measure reflectance in the visible to the non-visible light spectrum (i.e., blue $(475 \mathrm{~nm})$, green $(560 \mathrm{~nm})$, red $(668 \mathrm{~nm})$, red-edge $(717 \mathrm{~nm}), \mathrm{NIR}(840 \mathrm{~nm})$, and thermal $(8-14 \mathrm{~nm}))$ at a ground sampling distance of $9.6 \mathrm{~cm}$ per pixel (Figure $2 \mathrm{~b}$ ). The main advantage of this imaging platform is its ability to capture synchronised thermal and multispectral data simultaneously in an automated manner. A shapefile of the study area was created in Google Earth Pro and exported to the M300's handheld console to develop a UAV flight plan (Figure 2c). Before and post-flight, an automatic calibrated reflectance panel was used to compensate for incident light conditions by using known reflectance values across the spectrum to radiometrically calibrate the Altum sensor (Figure $2 \mathrm{~d}$ ). An automated flight mission was conducted at a flight height of $100 \mathrm{~m}$, with an image overlap of $80 \%$. An orthomosaic of the imagery derived from the imaging platform was generated and pre-processed in order to enhance image features using the Pix4D Fields photogrammetry software. 

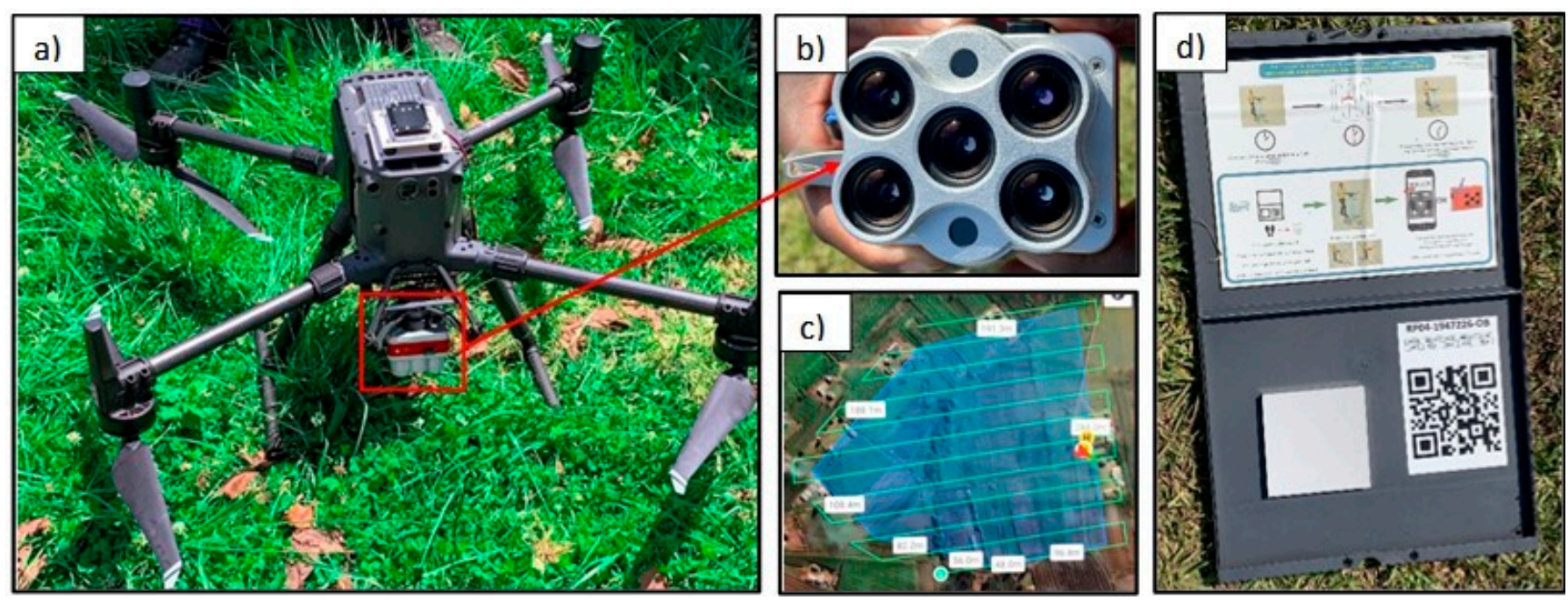

Figure 2. (a) Matrice $300 \mathrm{UAV}$ integrated with the Altum sensor serving as the imaging platform used in this study, (b) Altum camera, (c) flight plan for the study image, and (d) the calibrated reflectance panel.

Table 2. DJI M300 UAV specifications.

\begin{tabular}{cc}
\hline Parameter & Specification \\
\hline UAV type & Rotary wing \\
Weight & Approx. $4.53 \mathrm{~kg}$ \\
Size & 887 (width) $\times 880$ (length) $\times 378$ (height) $\mathrm{mm}$ \\
Flight duration & $55 \mathrm{~min}$ \\
Maximum speed & $27 \mathrm{~m} / \mathrm{s}$ \\
Maximum altitude & $7000 \mathrm{~m}$ \\
Maximum payload capacity & $2.7 \mathrm{~kg}$ \\
Maximum take-off weight & $6.14 \mathrm{~kg}$ \\
Maximum flight range & $7 \mathrm{~km}$ \\
Operating temperature & From -20 to $50{ }^{\circ} \mathrm{C}$ \\
\hline
\end{tabular}

\subsection{Model Development and Statistical Analysis}

2.4.1. Selection of Vegetation Indices

The UAV imaging platform used in this study measures reflectance in the visible, red-edge, and NIR regions of the spectrum; hence, we sought to evaluate all possible combinations of UAV spectral bands to accurately predict crop leaf water indicators. In this study, the reflectance data obtained from the Altum multispectral and thermal bands were used to derive vegetation indices (VIs). Table 3 shows a list of VIs that were selected for this study based on their direct and indirect correlation with plant water status indicators. As mentioned earlier, the prepared spectral data were then overlaid with the point data associated with measured maize water indicators to derive data that was used for the statistical prediction of maize water content. 
Table 3. List of vegetation indices (VIs) used in the modelling of crop water content and related source references.

\begin{tabular}{|c|c|c|c|}
\hline Index & Full Name & Formula & Reference \\
\hline \multicolumn{4}{|c|}{ Direct water-sensitive spectral VI } \\
\hline NDWI & Normalised Difference Water Index & Green - NIR/Green + NIR & [41] \\
\hline \multicolumn{4}{|c|}{ Indirect water-sensitive spectral VIs } \\
\hline NDVI & Normalised Difference Vegetation Index & NIR - Red/NIR + Red & [18] \\
\hline NGRDI & Normalised Difference Green/Red Index & Green - red/green + red & [42] \\
\hline NDRE & Normalised Difference Red-Edge Index & NIR - rededge/NIR + Rededge & {$[30]$} \\
\hline NDVI rededge & $\begin{array}{c}\text { Red-Edge Normalised Difference } \\
\text { Vegetation Index }\end{array}$ & Rededge - Red/Rededge + red & {$[30]$} \\
\hline CIgreen & Green Chlorophyll Index & (NIR/Green) -1 & [12] \\
\hline CIrededge & Red-edge chlorophyll index & $(\mathrm{NIR} /$ rededge $)-1$ & {$[30]$} \\
\hline
\end{tabular}

\subsubsection{Spatial Analysis}

The sampled data were randomly split into training $(70 \%)$ and validation data $(30 \%)$. The former was used in model development and the latter in assessing the accuracy of predictive models. A comparative analysis was conducted between the support vector regression, random forest regression, decision trees regression, artificial neural network regression, and the partial least squares regression algorithms in predicting the leaf water content indicators (i.e., EWT, FMC, and SLA). According to Lary et al. [43], RF, SVM, DT, ANN, and PLS are the most widely used machine learning algorithms in the geosciences. These non-parametric algorithms are robust, efficient, and can be parameterised and implemented with ease $[31,33]$. Above all, these algorithms have been used in the literature and are renowned for their accuracy, which is facilitated by their ability to optimally select spectral features for accurate predictions [43,44]. It is in this regard that these algorithms were chosen for this study. Then, variable selection was performed for each prediction model to identify the variables that are most influential in the prediction of the named indicators. Variable selection reduces issues associated with variable redundancy and multicollinearity, which affect the performance of regression models [45]. Details on how each algorithm was used in this study are provided below.

Support vector regression (SVR): Three parameters were tuned for the SVR model; more specifically, the penalty parameter $(C)$, precision parameter $(\varepsilon)$, and kernel parameter $(\gamma)$. In this study, the grid search and 10 -fold cross validation method, recommended by Shafiee, et al. [46], was performed on the training data and the SVR model was performed optimally at a $C$ value of 8 , the $\varepsilon$ equal to 0.5 , and the $\gamma$ kept at a default of 1 .

Random forest regression (RFR): The quality of the RFR model depends on the proper setting of the RFR hyperparameters. The RFR model is generally optimised based on two parameters, namely Ntree, which is the number of decision trees to be generated, and Mtry, the number of predictor variables tested for the best split when growing the trees [47]. The optimal hyperparameter values for the prediction of maize water content in the study was determined to be an Ntree equal to 500 and an Mtry of 11 after numerous iterations.

Decision tree regression (DTR): In this study, the fine-tuning process of the DTR algorithm was performed until no improvements were observed and the model parameters were specified. The minimum split, which is the minimum number of values that must exist at a node before the split is attempted [48], was fixed at 20. The maximum depth to which the tree is allowed to grow was set at 30 . Finally, the termination criteria for the regression tree was specified at 0.01 . These parameters were identified after numerous iterations and errors had been noted.

Artificial neural network (ANNR): The hyperparameters of the ANNR algorithm were fine-tuned to decrease the error of prediction and improve the accuracy of the model. As such, the hyperparameters of the optimal ANNR model was determined to be 10 nodes and 2 hidden layers.

Partial least squares regression (PLSR): The optimal PLSR model was obtained from the model that yielded the minimum relative error. The forward selection and backward 
elimination technique was used to select the optimal predictor and PLSR model that was used in this study. The optimal PLSR model was characterised by the least impact of multicollinearity and the greatest prediction accuracy.

To optimise the outputs of the abovementioned models, the variable importance scores were used to determine the most influential bands and indices for estimating leaf water content indicators [49]. The least important predictor variables were progressively removed and the model was re-developed [49,50]. The Caret Package was used to develop the regression models in the RStudio software version 1.4.1564.

\subsection{Accuracy Assessment of Derived Maize Water Content Models}

An accuracy assessment was conducted to evaluate the performance of regression models in predicting leaf water content indicators. The coefficient of determination $\left(R^{2}\right)$, the root mean square error (RMSE), and the relative root mean square error (rRMSE) were used to compare the accuracy of different models. More specifically, the $\mathrm{R}^{2}$ was used to measure the variation between measured and predicted maize leaf water content, and the RMSE was used to assess the magnitude of error between the field measurements and the modelled water content. The rRMSE was used to compare the performance of regression models across different algorithms and maize water indicators. To compute rRMSE, the RMSEs from each model were normalised using the mean of each variable and then expressed as a percentage [51].

\section{Results}

\subsection{Descriptive Analysis of Maize Crop Water Indicators and Measured Biophysical Variables}

A wide range of variations was recorded in both the biophysical variables and the crop water indicators of maize crops. Table 4 represents the descriptive statistics of leaf FW, DW, Leaf area, EWT, FMC, and SLA. Averages for FW, DW, and Leaf area were $37.06 \mathrm{~g}$, $6.94 \mathrm{~g}$, and $0.09 \mathrm{~m}^{2}$, respectively, while the averages for crop water indicators, particularly $\mathrm{EWT}_{\text {leaf }}, \mathrm{FMC}_{\text {leaf }}$, and $\mathrm{SLA}_{\text {leaf }}$ were $356.52 \mathrm{gm}^{-2}, 81.27 \%, 29.86 \mathrm{gm}^{-2}$, and $0.01 \mathrm{~m}^{2} \mathrm{~g}^{-1}$, respectively. A Kolmogorov-Smirnov normality test revealed that all crop water indicators did not deviate significantly from the normal distribution curve.

Table 4. Descriptive statistics of crop water indicators and biophysical variables.

\begin{tabular}{ccccccc}
\hline Parameter & $\begin{array}{c}\text { Range } \\
\text { (Min-Max) }\end{array}$ & Mean & Median & Std. & CV \% & SEM \\
\hline FW $(\mathrm{g})$ & $31.02-45.52$ & 37.06 & 36.73 & 3.82 & 10.31 & 0.53 \\
DW $(\mathrm{g})$ & $3.22-8.76$ & 6.94 & 6.95 & 1.02 & 14.69 & 0.14 \\
Leaf area $\left(\mathrm{m}^{2}\right)$ & $0.06-0.10$ & 0.09 & 0.09 & 0.01 & 10.53 & 0.00 \\
\hline & \multicolumn{7}{c}{ Ciophysical variables } \\
EWT $_{\text {leaf }}\left(\mathrm{gm}^{-2}\right)$ & $290.91-473.18$ & 356.52 & 344.14 & 42.42 & 11.90 & 5.88 \\
FMC $_{\text {leaf }}(\%)$ & $77.84-91.39$ & 81.27 & 81.24 & 1.89 & 2.33 & 0.26 \\
SLA $_{\text {leaf }}\left(\mathrm{m}^{2} \mathrm{~g}^{-1}\right)$ & $0.0009-0.025$ & 0.01 & 0.01 & 0.00 & 18.16 & 0.00 \\
\hline
\end{tabular}

SEM is the standard error of mean, Std. is the standard deviation, and CV is the coefficient of variation.

\subsection{Evaluation of Maize Water Indicators and Optimised Regression Models}

Table 5 illustrates the model accuracies obtained in predicting leaf EWT, FMC, and SLA based on the RFR, DTR, ANNR, PLSR, and SVR regression techniques. The accuracies of the prediction models varied greatly for the crop water indicators. 
Table 5. Prediction accuracies of $\mathrm{EWT}_{\text {leaf }}, \mathrm{FMC}_{\text {leaf }}$, and $\mathrm{SLA}_{\text {leaf }}$ were derived using optimal models based on the RFR, DTR, ANNR, PLSR, and SVR regression models.

\begin{tabular}{cccccccccc}
\hline \multirow{2}{*}{ Model } & \multicolumn{3}{c}{ EWT $_{\text {leaf }}\left(\mathbf{g m}^{-\mathbf{2}}\right)$} & \multicolumn{3}{c}{ FMC $_{\text {leaf }}(\mathbf{\%})$} & \multicolumn{3}{c}{ SLA $_{\text {leaf }}\left(\mathbf{m}^{\mathbf{2}} \mathbf{g}^{-\mathbf{1}}\right)$} \\
\cline { 2 - 10 } & $\mathbf{R}^{\mathbf{2}}$ & RMSE & RRMSE & $\mathbf{R}^{\mathbf{2}}$ & RMSE & RRMSE & $\mathbf{R}^{\mathbf{2}}$ & RMSE & RRMSE \\
\hline RFR & 0.89 & 1028 & 313 & 0.76 & 0.45 & 1.00 & 0.73 & 0.0004 & 3.48 \\
DTR & 0.73 & 25.16 & 7.67 & 0.65 & 1.08 & 1.35 & 0.7 & 0.0009 & 8.16 \\
ANNR & 0.84 & 14.29 & 4.35 & 0,34 & 1.54 & 1.92 & 0.68 & 0.0007 & 6.60 \\
PLSR & 0.74 & 17.1 & 5.15 & 0.45 & 0.48 & 0.60 & 0.6 & 0.0008 & 19.33 \\
SVR & 0.78 & 15.05 & 4.76 & 0.69 & 0.70 & 0.89 & 0.71 & 0.0005 & 18.82 \\
\hline
\end{tabular}

For example, when estimating $\mathrm{EWT}_{\text {leaf }}$, the DTR yielded the poorest model, with an RMSE of $25.16 \mathrm{gm}^{-2}$ and an $\mathrm{R}^{2}$ of 0.73 . The prediction of $\mathrm{EWT}_{\text {leaf }}$ improved slightly for the PLSR model $\left(\right.$ RMSE $=17.1 \mathrm{gm}^{-2}$ and $\left.\mathrm{R}^{2}=0.74\right)$. Similarly, the SVR and the ANNR models predicted $\mathrm{EWT}_{\text {leaf }}$ at an improved RMSE $=15.05 \mathrm{gm}^{-2}, \mathrm{R}=0.76$, and RMSE $=14.29 \mathrm{gm}^{-2}$, $R^{2}=0.84$, respectively. The optimal algorithm for estimating $E W T_{\text {leaf }}$ was derived from the RFR model with an RMSE of $10.28 \mathrm{gm}^{-2}$ and an $\mathrm{R}^{2}$ of 0.89 (Table 5).

Similarly, the ANNR model exhibited the lowest prediction accuracy in estimating $F_{\text {FMC }}$ leaf $\left(R M S E=1.54 \%\right.$ and $\left.R^{2}=0.34\right)$. This was followed by the PLSR, with an RMSE of $0.48 \%$ and an $R^{2}$ of 0.45 . The prediction accuracy increased significantly with the DTR and the SVR models, with an $R^{2}=0.65$ and an $R^{2}=0.69$, respectively. The RFR model optimally predicted the $\mathrm{FMC}_{\text {leaf }}$ with the lowest $\mathrm{RMSE}=0.45 \%$ and $\mathrm{R}^{2}=0.76$ (Table 5).

When predicting SLA leaf, the lowest RMSE of $0.0008 \mathrm{~g}^{-1} \mathrm{~m}^{2}$ and $\mathrm{R}^{2}$ of 0.6 was obtained using the PLSR model. The ANNR model improved the prediction by a magnitude of 8 , i.e., $R^{2}=0.68$. The ability of the DTR and SVR to predict SLA differed slightly with an RMSE $=0.0009 \mathrm{~m}^{2} \mathrm{~g}^{-1}$ and $\mathrm{R}^{2}=0.7$, and an RMSE $=0.0005 \mathrm{~g}^{-1} \mathrm{~m}^{2}$ and $\mathrm{R}^{2}=0.71$, respectively. The optimal model for estimating $\mathrm{SLA}_{\text {leaf }}$ exhibited an RMSE of $0.0004 \mathrm{~g}^{-1} \mathrm{~m}^{2}$ and $\mathrm{R}^{2}$ of 0.73 (Table 5).

\subsection{Optimal Models for Estimating Maize Water Content Indicators}

Figure 3 illustrates the results obtained when all maize water content indicators were estimated based on the optimal regression models. The EWT leaf performed optimally as an indicator of maize water content, with an rRMSE of $3.13 \%$ and an $R^{2}$ of 0.89 . The most optimal variables that were selected for estimating EWT leaf were NDVI, NIR, NDWI, CIgreen, NDVI rededge, Red, CIrededge, NDRE, and NGRDI, in order of importance (Figure 3A).

Meanwhile, the $\mathrm{FMC}_{\text {leaf }}$ based on the PLSR model performed better than EWT leaf by a magnitude of $2.53 \%$, with an rRMSE of $0.6 \%$. The most suitable predictor variables included NDRE, NIR, NDWI, CIrededge, NDVI rededge, red-edge, CIgreen, blue, thermal, NDVI, red, and the green band (Figure 3B). Additionally, the FMC leaf $_{\text {SVR model produced }}$ a relatively high rRMSE of $0.89 \%$. However, although the rRMSE of these $F M C_{\text {leaf }}$ models were high, there was a high variation between the measured and estimated $\mathrm{FMC}_{\text {leaf }}$ values, with an $\mathrm{R}^{2}$ of 0.45 and 0.69 , respectively. In comparison, the $\mathrm{FMC}_{\text {leaf }}$ based on the RFR model exhibited an optimally high $R^{2}$ of 0.76 and an acceptable rRMSE of $1 \%$, making it the optimal $\mathrm{FMC}_{\text {leaf }}$ model.

The optimal model for the prediction of maize $S_{\text {LA }}$ leaf exhibited an rRMSE of 3.48\% and an $\mathrm{R}^{2}=0.73$. The variables that had the highest influence in the SLA model were the NDVI, Thermal, NIR, NDRE, CIgreen, red-edge, NDVI rededge, CIrededge, NGRDI, and the NDWI, in order of descending importance (Figure 3C).

The results revealed that the optimal indicators of maize water content based on the RFR models were $\mathrm{FMC}_{\text {leaf }}$ and $\mathrm{EWT}_{\text {leaf }}$, followed by $\mathrm{SLA}_{\text {leaf }}$. Additionally, the UAV multispectral bands and derived VIs were successful in predicting all maize water content indicators. 

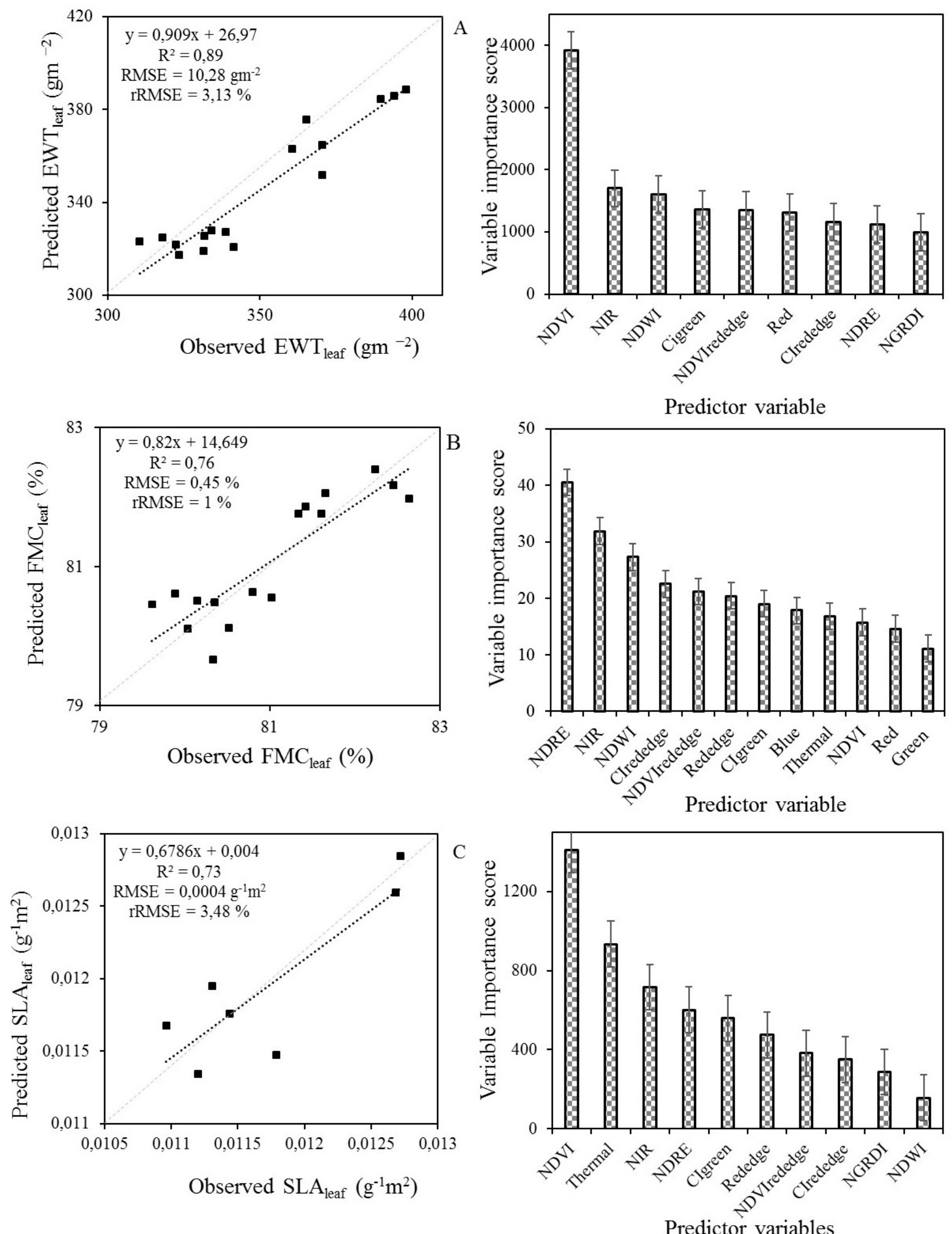

Figure 3. Relationship between the predicted and observed (A) $\mathrm{EWT}_{\text {leaf }},(\mathbf{B}) \mathrm{FMC}_{\text {leaf }}$, and (C) SLA leaf of maize derived using optimal predictor variables and the model variable importance scores. 


\subsection{Mapping the Spatial Distribution of Maize Leaf Water Content Indicators}

The spatial distribution of leaf EWT, FMC, and SLA was estimated based on the optimal models. Figure 4 illustrates the spatial distribution of maize water content indicators. It can be observed that the water content of maize is relatively high throughout the maize fields and seem to decrease towards the edge of the maize plot, with the exception of FMC, which revealed small patches of lower maize water content within maize fields.
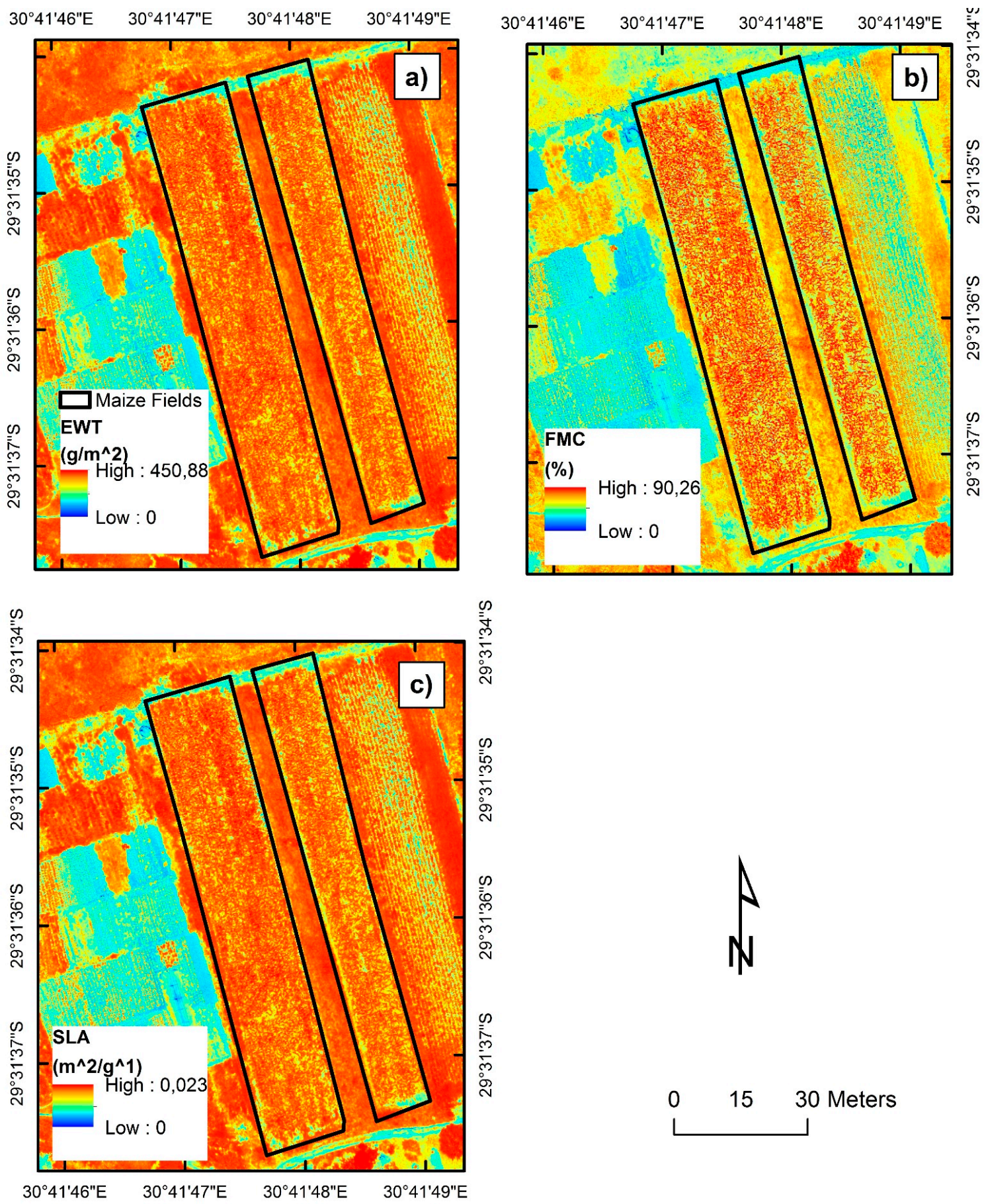

Figure 4. Spatial distribution of (a) $\mathrm{EWT}_{\text {leaf }}$ (b) $\mathrm{FMC}_{\text {leaf }}$, and (c) $\mathrm{SLA}_{\text {leaf }}$ of smallholder maize crops. 


\section{Discussion}

Smallholder farmers are frequently faced with the need to optimise maize production; therefore, an assessment of maize water status through the monitoring of EWT, FMC, and SLA could provide essential information for the improvement of crop-water use efficiency and the enhancement of maize productivity under water-limited conditions [52]. The essence of this study was to assess and identify a suitable indicator for maize water content and to evaluate the predictive performance of robust algorithms in predicting maize water status. Thus, this study sought to investigate the use of UAV-derived remotely sensed data and machine learning techniques in estimating maize EWT, FMC, and SLA.

\subsection{Estimating Maize Water Content Indicators}

Results in this study indicate that when estimating maize equivalent water thickness, an optimal prediction $\left(\mathrm{rRMSE}=3.13 \%\right.$ and $\mathrm{R}^{2}=0.89$ ) can be obtained based on spectral variables derived from the NIR section of the electromagnetic spectrum (NDVI, NIR, NDWI, and NDRE). The literature confirms that the quantity of water in crop leaves is statistically correlated with leaf reflectance across the spectrum [26]. More specifically, the variation in water molecules present in the leaf cell strongly influences the reflectance of solar radiation in the NIR region; hence, this section of the spectrum is commonly used to quantity leaf water status [8,52]. The variation in leaf reflectance is related to plant vigour, which is primarily controlled by the changes in leaf cuticles, mesophyll thickness, and intercellular air spaces as a result of leaf water and nutrient availability [20,53]. Furthermore, the NIR section has widely proven to be related to the leaf water absorption zone, hence its optimal influence in estimating the leaf EWT of maize in smallholder farms. Correspondingly, studies by Mobasheri and Fatemi [54] and Riaño, et al. [55] successfully illustrated the use of leaf optical reflectance in the NIR section of the electromagnetic spectrum for optimally predicting EWT with an $\mathrm{R}^{2}$ of 0.95 and 0.75 , respectively. EWT also displayed high sensitivity to chlorophyll-based indices, especially CIgreen and CIrededge. This could be explained by the fact that changes in the level of chlorophyll in leaves, which alters crop greenness and leaf pigmentation, is closely related to water status $[12,56]$. As in this study, Zhang and Zhou [30] noted that these chlorophyll-based indices presented a higher sensitivity to crop water indicators.

Fuel moisture content (FMC) was optimally predicted to an rRMSE of $1 \%$ and an $\mathrm{R}^{2}=0.76$. The results of this study show that FMC is particularly sensitive to the rededge waveband and associated derivatives of these spectral channels. For instance, there was a significant influence of the red-edge, NDRE, NDVI rededge, and CIrededge in the prediction of maize FMC. Such sensitivity of the red-edge band in predicting FMC can be explained by its positive association with crop biomass as well as chlorophyll content, which is also positively correlated with FMC [20]. Generally, the variations in crop water content are largely associated with chlorophyll activity and leaf area index, which influence the reflectance of leaf tissue in the red-edge section of the electromagnetic spectrum [57]. This was the case in studies by Bar-Massada and Sviri [58] and Cao and Wang [59], which confirmed a variation in the reflectance of green leaves under water-stressed conditions in the red-edge band, making this wavelength a significant predictor of FMC.

Furthermore, NDWI, which is primarily derived from the NIR band, has a significant influence on the prediction of FMC. This VI is particularly important in predicting water content as it is sensitive to the variations of leaf reflectance induced by water molecules and dry matter content, and hence, strongly correlates to plant water stress [12]. A study by Sow, et al. [60] demonstrated the importance of the NDWI in predicting FMC by achieving an $\mathrm{R}^{2}$ of 0.85 . In this regard, the literature supports the relationship between FMC and the red-edge as well as the NIR sections of the electromagnetic spectrum [20,57].

Finally, the results in this study show that SLA could be estimated to an rRMSE of $3.48 \%$ and an $\mathrm{R}^{2}$ of 0.73 . SLA was particularly sensitive to the UAV-derived thermal, NIR, and red-edge wavelengths. When crops are in a state of water deficit, there is an overall increase in crop surface temperature due to the closure of leaf stoma, which decreases 
the evaporation cooling effect [61]. In this regard, the literature notes the fact that the thermal band has been well-established as a key wavelength for early plant water stress detection [61,62]. Again, NDVI was the most influential predictor of maize SLA in this study. This could be explained by the fact that NDVI is proportional to chlorophyll content, which is sensitive to the changes in crop water content [63]. Furthermore, when crops are water-stressed, there is a decrease in the absorption of chlorophyll at the red wavelength and a decrease in reflectance at the NIR region due to the shrinkage of leaf thickness during the wilting process [64]. In a similar study, Ali, et al. [65] noted that NDVI was very effective in optimally estimating SLA $\left(R^{2}=0.73\right.$ and RMSE $\left.=4.68 \%\right)$. Wijewardana, Alsajri, Irby, Krutz, Golden, Henry, Gao and Reddy [26] confirm that the combination of both the NIR and red wavelengths allows NDVI to be an invaluable predictor of photosynthetic activity and long-term water stress. Additionally, SLA was sensitive to the NDRE, NDVI redege as well as chlorophyll-based VIs. The influence of these red-edge-based VIs in predicting SLA stems from the fact that the variations in leaf thickness and area, as well as leaf pigmentation due to water stress, is promptly detected at the red-edge section [66]. In this regard, the variations in leaf photosynthetic capacity provides essential information pertaining to maize leaf water vapour and water content [65].

Furthermore, the results illustrate that all maize leaf water content indicators were optimally predicted using UAV-derived data. Accordingly, FMC and EWT yielded the highest predictive power of water content, while SLA was effectively estimated. In comparison, the FMC and EWT are the most ideal crop water indicators for monitoring water stress using field spectroscopy techniques $[13,16]$.

\subsection{The Performance of Machine Learning Algorithms in Predicting Maize Water Content Indicators}

Results in this study show that the RFR approach is the most suitable explorative tool for predicting all maize water content indicators. For instance, RFR optimally predicted FMC, EWT, and SLA, producing the highest prediction accuracy (rRMSE $=1 \%, 3.13 \%$, and $3.48 \%$ ). The RFR algorithm can effectively establish the relationship between leaf reflectance and maize water at farm scale. The strength of RFR could be explained by the fact that the algorithm is not highly affected by noise in the data, hence there is a reduced risk of producing overfitting models $[67,68]$. In a similar study, Sibanda, Onisimo, Dube and Mabhaudhi [20] confirmed the robustness of the RFR model in modelling water content elements, particularly the FMC, by achieving optimal $\mathrm{R}^{2}$ s as high as 1 and an RMSE of $16.4 \%$.

The SVR approach was also optimal in predicting maize leaf EWT, FMC, and SLA. The strength of the SVR lies in its ability to circumvent outliers and exhibit a high generalisation capacity to handle unseen patterns [69]. The results in this study reveal that the SVR is similar to the RFR in predictive power. This could be explained by the fact that the SVR and RFR ensembles optimally operate with a relatively small number of training samples, which is often the case for data acquired at the field scale after avoiding spatial autocorrelation $[63,68]$. Therefore, the results of this study demonstrate that the model properties of RFR and SVR are well suited for the estimation of smallholder maize water content. Generally, DTR did not perform well in predicting maize water indicators. This could be explained by the fact that DTR does not have features such as the bootstrapping in RFR and hyperplanes in SVR for effectively encompassing all the samples during the prediction procedure [69]. This can result in the DTR algorithm being conservative in its prediction procedure, hence exhibiting lower prediction accuracies. In this regard, there are very few studies that have evaluated its predictive performance in the context of canopy and leaf water content. In comparison, the ANN and PLSR exhibited poorer performance in predicting maize water content. This could be due to the fact that both the ANN and PLSR are best suited for large training datasets in order to produce credible results $[63,70]$. Thus, this study prompts future studies to investigate the optimal sample size required to produce accurate predictions of smallholder maize water content when using a combination of UAV imagery and machine learning techniques. Additionally, there 
are prospects to evaluate the ability of other empirical models and deep learning methods to accurately model maize water variability.

\section{Conclusions}

The present study tested the utility of unmanned aerial vehicle (UAV)-based multispectral data in a comparative approach of estimating water content using random forest regression (RFR), support vector regression (SVR), decision tree regression (DTR), artificial neural network (ANNR), and partial least squares regression (PLSR) machine learning techniques and the equivalent water thickness (EWT), fuel moisture content (FMC), and specific leaf area (SLA) of maize crops in smallholder farms. Based on the findings of the study, it can be concluded that:

- $\quad$ The EWT, FMC, and SLA water content indicators of maize could be optimally predicted using the NIR and red-edge-derived spectral variables;

- $\quad$ The RFR and SVR modelling techniques have a more robust capacity for predicting water content indicators of maize in comparison to the DTR, ANNR, and PLSR;

- $\quad$ FMC and EWT, in concert with the RFR approach, exhibited the highest predictive performance, and are therefore valid indicators of maize water content.

This study demonstrates that UAV-derived multispectral data is capable of predicting maize water variations of smallholder farms with exceptional accuracy and can hence complement and inform farms on drought-related water stress. However, there are research gaps that demand further inquiry, particularly on smallholder maize farms. Future studies should aim to evaluate the utility of UAV-derived data and the optimal water indicators for characterising the variation of maize water content across different phenological stages. Furthermore, a key limitation of this study is the lack of the SWIR spectrum, which would be valuable as it is an essential water absorption band. Therefore, additional studies are necessary to evaluate whether UAV sensors that measure spectral reflectance along with the SWIR section of the electromagnetic spectrum can improve the prediction of smallholder maize water content. Finally, this study was site and crop-specific; therefore, studies conducted across various climates, different smallholder crops, and at a multitemporal scale should be assessed to draw broader conclusions in the characterisation of crop water stress.

Author Contributions: Conceptualization, H.S.N., M.S., T.M., O.M., V.G.P.C. and J.O.; methodology, H.S.N., M.S., T.M., O.M., V.G.P.C. and J.O.; software, H.S.N., M.S. and A.C.; validation, H.S.N., M.S. and J.O.; formal analysis, H.S.N. and M.S.; investigation, H.S.N., M.S., T.M., O.M., V.G.P.C. and J.O.; resources, J.O., O.M. and TM.; data curation, H.S.N.; writing — original draft preparation, H.S.N. and M.S.; writing-review and editing, H.S.N., M.S., J.O.,T.M., O.M. and V.G.P.C.; supervision, J.O. and M.S.; project administration, M.S., T.M. and V.G.P.C.; funding acquisition, T.M. and O.M. All authors have read and agreed to the published version of the manuscript.

Funding: This work was funded by the Water Research Commission of South Africa (WRC) through the Project WRC K5/2971/ / 4 titled the "Use of drones in monitoring crop health, water stress, crop water requirements, and improvements on crop water productivity to enhance precision agriculture and irrigation scheduling", and in part by the National Research Foundation of South Africa (NRF) Research Chair in Land Use Planning and Management (Grant Number: 84157) as well as NRF Grant Number 119409.

Data Availability Statement: The data presented in this study are available on request from the corresponding author. The data are not publicly available due to authorisation restrictions from the funder that limit the distribution of data as the article is part of an ongoing project where other manuscripts are still being prepared.

Acknowledgments: The authors would like to recognise the support of the Centre for Transformative Agricultural and Food Systems through the uMngeni Resilience Project, which is funded by the Adaptation Fund. The authors also wish to thank Vivek Naiken, Siphiwokuhle Buthelezi, Trylee Matongera, Israel Odebiri, Serge Kiala, Welcome Ngcobo, Amanda Nyawose, and Kiara Brewer for their assistance with fieldwork and laboratory logistics. 
Conflicts of Interest: The authors declare no conflict of interest.

\section{References}

1. Avetisyan, D.; Cvetanova, G. Water Status Assessment in Maize and Sunflower Crops Using Sentinel-2 Multispectral Data. Space Ecol. Saf. 2019, 152-157.

2. Ngoune Tandzi, L.; Mutengwa, C.S. Estimation of maize (Zea mays L.) yield per harvest area: Appropriate methods. Agronomy 2020, 10, 29. [CrossRef]

3. Agbugba, I.; Christian, M.; Obi, A. Economic analysis of smallholder maize farmers: Implications for public extension services in Eastern Cape. S. Afr. J. Agric. Ext. 2020, 48, 50-63.

4. Sibanda, M.; Mutanga, O.; Dube, T.; Odindi, J.; Mafongoya, P.L. The Utility of the Upcoming HyspIRI's Simulated Spectral Settings in Detecting Maize Gray Leafy Spot in Relation to Sentinel-2 MSI, VEN $\mu$ S, and Landsat 8 OLI Sensors. Agronomy 2019, 9 , 846. [CrossRef]

5. Gomez y Paloma, S.; Riesgo, L.; Louhichi, K. The Role of Smallholder Farms in Food and Nutrition Security; Springer Nature: Cham, Switzerland, 2020.

6. Daryanto, S.; Wang, L.; Jacinthe, P.-A. Global synthesis of drought effects on maize and wheat production. PLoS ONE 2016, 11, e0156362. [CrossRef]

7. Zhang, L.; Zhang, H.; Niu, Y.; Han, W. Mapping maize water stress based on UAV multispectral remote sensing. Remote Sens. 2019, 11, 605. [CrossRef]

8. Pasqualotto, N.; Delegido, J.; Van Wittenberghe, S.; Verrelst, J.; Rivera, J.P.; Moreno, J. Retrieval of canopy water content of different crop types with two new hyperspectral indices: Water Absorption Area Index and Depth Water Index. Int. J. Appl. Earth Obs. Geoinf. 2018, 67, 69-78. [CrossRef]

9. Chivasa, W.; Mutanga, O.; Biradar, C. UAV-Based Multispectral Phenotyping for Disease Resistance to Accelerate Crop Improvement under Changing Climate Conditions. Remote Sens. 2020, 12, 2445. [CrossRef]

10. Afzal, A.; Mousavi, S.-F. Estimation of moisture in maize leaf by measuring leaf dielectric constant. Int. J. Agric. Biol. 2008, 10, 66-68.

11. Davidson, A.; Wang, S.; Wilmshurst, J. Remote sensing of grassland-shrubland vegetation water content in the shortwave domain. Int. J. Appl. Earth Obs. Geoinf. 2006, 8, 225-236. [CrossRef]

12. Zhang, F.; Zhou, G. Estimation of canopy water content by means of hyperspectral indices based on drought stress gradient experiments of maize in the north plain China. Remote Sens. 2015, 7, 15203-15223. [CrossRef]

13. Liu, S.; Peng, Y.; Du, W.; Le, Y.; Li, L. Remote estimation of leaf and canopy water content in winter wheat with different vertical distribution of water-related properties. Remote Sens. 2015, 7, 4626-4650. [CrossRef]

14. Zhang, C.; Pattey, E.; Liu, J.; Cai, H.; Shang, J.; Dong, T. Retrieving leaf and canopy water content of winter wheat using vegetation water indices. IEEE J. Sel. Top. Appl. Earth Obs. Remote Sens. 2017, 11, 112-126. [CrossRef]

15. Zhou, H.; Zhou, G.; He, Q.; Zhou, L.; Ji, Y.; Zhou, M. Environmental explanation of maize specific leaf area under varying water stress regimes. Environ. Exp. Bot. 2020, 171, 103932. [CrossRef]

16. Yi, Q.; Wang, F.; Bao, A.; Jiapaer, G. Leaf and canopy water content estimation in cotton using hyperspectral indices and radiative transfer models. Int. J. Appl. Earth Obs. Geoinf. 2014, 33, 67-75. [CrossRef]

17. González, J.A.; Gallardo, M.; Hilal, M.B.; Rosa, M.D.; Prado, F.E. Physiological responses of quinoa (Chenopodium quinoa) to drought and waterlogging stresses: Dry matter partitioning. Bot. Stud. 2009, 50, 35-42.

18. Ali, A.M.; Darvishzadeh, R.; Skidmore, A.K.; van Duren, I. Specific leaf area estimation from leaf and canopy reflectance through optimization and validation of vegetation indices. Agric. For. Meteorol. 2017, 236, 162-174. [CrossRef]

19. Yue, J.; Feng, H.; Jin, X.; Yuan, H.; Li, Z.; Zhou, C.; Yang, G.; Tian, Q. A comparison of crop parameters estimation using images from UAV-mounted snapshot hyperspectral sensor and high-definition digital camera. Remote Sens. 2018, 10, 1138. [CrossRef]

20. Sibanda, M.; Onisimo, M.; Dube, T.; Mabhaudhi, T. Quantitative assessment of grassland foliar moisture parameters as an inference on rangeland condition in the mesic rangelands of southern Africa. Int. J. Remote Sens. 2021, 42, 1474-1491. [CrossRef]

21. Xu, C.; Qu, J.J.; Hao, X.; Cosh, M.H.; Zhu, Z.; Gutenberg, L. Monitoring crop water content for corn and soybean fields through data fusion of MODIS and Landsat measurements in Iowa. Agric. Water Manag. 2020, 227, 105844. [CrossRef]

22. Krishna, G.; Sahoo, R.N.; Singh, P.; Patra, H.; Bajpai, V.; Das, B.; Kumar, S.; Dhandapani, R.; Vishwakarma, C.; Pal, M. Application of thermal imaging and hyperspectral remote sensing for crop water deficit stress monitoring. Geocarto Int. 2021, 36, 481-498. [CrossRef]

23. Hussain, S.; Gao, K.; Din, M.; Gao, Y.; Shi, Z.; Wang, S. Assessment of UAV-Onboard Multispectral Sensor for non-destructive site-specific rapeseed crop phenotype variable at different phenological stages and resolutions. Remote Sens. 2020, $12,397$. [CrossRef]

24. Maes, W.H.; Huete, A.R.; Avino, M.; Boer, M.M.; Dehaan, R.; Pendall, E.; Griebel, A.; Steppe, K. Can UAV-based infrared thermography be used to study plant-parasite interactions between mistletoe and eucalypt trees? Remote Sens. 2018, 10, 2062. [CrossRef]

25. Castaldi, F.; Pelosi, F.; Pascucci, S.; Casa, R. Assessing the potential of images from unmanned aerial vehicles (UAV) to support herbicide patch spraying in maize. Precis. Agric. 2017, 18, 76-94. [CrossRef] 
26. Wijewardana, C.; Alsajri, F.A.; Irby, J.T.; Krutz, L.J.; Golden, B.; Henry, W.B.; Gao, W.; Reddy, K.R. Physiological assessment of water deficit in soybean using midday leaf water potential and spectral features. J. Plant. Interact. 2019, 14, 533-543. [CrossRef]

27. Zhang, J.; Basso, B.; Price, R.F.; Putman, G.; Shuai, G. Estimating plant distance in maize using Unmanned Aerial Vehicle (UAV). PLoS ONE. 2018, 13, e0195223. [CrossRef]

28. Han, L.; Yang, G.; Dai, H.; Yang, H.; Xu, B.; Feng, H.; Li, Z.; Yang, X. Fuzzy Clustering of Maize Plant-Height Patterns Using Time Series of UAV Remote-Sensing Images and Variety Traits. Front. Plant. Sci. 2019, 10, 926. [CrossRef]

29. Wahab, I.; Hall, O.; Jirström, M. Remote sensing of yields: Application of uav imagery-derived ndvi for estimating maize vigor and yields in complex farming systems in sub-saharan africa. Drones 2018, 2, 28. [CrossRef]

30. Zhang, F.; Zhou, G. Estimation of vegetation water content using hyperspectral vegetation indices: A comparison of crop water indicators in response to water stress treatments for summer maize. BMC Ecol. 2019, 19, 18. [CrossRef]

31. Yue, J.; Feng, H.; Yang, G.; Li, Z. A comparison of regression techniques for estimation of above-ground winter wheat biomass using near-surface spectroscopy. Remote Sens. 2018, 10, 66. [CrossRef]

32. Lu, B.; He, Y. Evaluating Empirical Regression, Machine Learning, and Radiative Transfer Modelling for Estimating Vegetation Chlorophyll Content Using Bi-Seasonal Hyperspectral Images. Remote Sens. 2019, 11, 1979. [CrossRef]

33. Liakos, K.G.; Busato, P.; Moshou, D.; Pearson, S.; Bochtis, D. Machine learning in agriculture: A review. Sensors 2018, 18, 2674. [CrossRef] [PubMed]

34. Jin, X.; Shi, C.; Yu, C.Y.; Yamada, T.; Sacks, E.J. Determination of Leaf Water Content by Visible and Near-Infrared Spectrometry and Multivariate Calibration in Miscanthus. Front. Plant. Sci. 2017, 8, 721. [CrossRef] [PubMed]

35. Ghooshchi, F.; Seilsepour, M.; Jafari, P. Effects of water stress on yield and some agronomic traits of maize (SC 301). Am. Eurasian J. Agric. Environ. Sci. 2008, 4, 302-305.

36. Mi, N.; Cai, F.; Zhang, Y.; Ji, R.; Zhang, S.; Wang, Y. Differential responses of maize yield to drought at vegetative and reproductive stages. Plant Soil Environ. 2018, 64, 260-267.

37. Mulla, D.J. Twenty five years of remote sensing in precision agriculture: Key advances and remaining knowledge gaps. Biosyst. Eng. 2013, 114, 358-371. [CrossRef]

38. Zhang, L.; Niu, Y.; Zhang, H.; Han, W.; Li, G.; Tang, J.; Peng, X. Maize canopy temperature extracted from UAV thermal and RGB imagery and its application in water stress monitoring. Front. Plant Sci. 2019, 10, 1270. [CrossRef]

39. Wahbi, A.; Avery, W. In Situ Destructive Sampling. In Cosmic Ray Neutron Sensing: Estimation of Agricultural Crop Biomass Water Equivalent; Springer: Cham, Switzerland, 2018; pp. 5-9.

40. Sade, N.; Galkin, E.; Moshelion, M. Measuring Arabidopsis, tomato and barley leaf relative water content (RWC). Bio Protoc. 2015, 5, e1451. [CrossRef]

41. Ozelkan, E. Water body detection analysis using NDWI indices derived from landsat-8 OLI. PoL J. Environ. Stud. 2020, 29, 1759-1769. [CrossRef]

42. Hoffmann, H.; Jensen, R.; Thomsen, A.; Nieto, H.; Rasmussen, J.; Friborg, T. Crop water stress maps for an entire growing season from visible and thermal UAV imagery. Biogeosciences 2016, 13, 6545-6563. [CrossRef]

43. Lary, D.J.; Alavi, A.H.; Gandomi, A.H.; Walker, A.L. Machine learning in geosciences and remote sensing. Geosci. Front. 2016, 7, 3-10. [CrossRef]

44. Yeganefar, A.; Niknam, S.A.; Asadi, R. The use of support vector machine, neural network, and regression analysis to predict and optimize surface roughness and cutting forces in milling. Int. J. Adv. Manuf. Technol. 2019, 105, 951-965. [CrossRef]

45. Chivasa, W.; Mutanga, O.; Burgueño, J. UAV-based high-throughput phenotyping to increase prediction and selection accuracy in maize varieties under artificial MSV inoculation. Comput. Electron. Agric. 2021, 184, 106128. [CrossRef]

46. Shafiee, S.; Lied, L.M.; Burud, I.; Dieseth, J.A.; Alsheikh, M.; Lillemo, M. Sequential forward selection and support vector regression in comparison to LASSO regression for spring wheat yield prediction based on UAV imagery. Comput. Electron. Agric. 2021, 183, 106036. [CrossRef]

47. Belgiu, M.; Dragut, L. Random forest in remote sensing: A review of applications and future directions. SPRS J. Photogramm. Remote Sens. 2016, 114, 24-31. [CrossRef]

48. Furuya, D.E.G.; Aguiar, J.A.F.; Estrabis, N.V.; Pinheiro, M.M.F.; Furuya, M.T.G.; Pereira, D.R.; Gonçalves, W.N.; Liesenberg, V.; Li, J.; Marcato Junior, J. A Machine Learning Approach for Mapping Forest Vegetation in Riparian Zones in an Atlantic Biome Environment Using Sentinel-2 Imagery. Remote Sens. 2020, 12, 4086. [CrossRef]

49. Speiser, J.L.; Miller, M.E.; Tooze, J.; Ip, E. A comparison of random forest variable selection methods for classification prediction modeling. Expert Syst. Appl. 2019, 134, 93-101. [CrossRef]

50. Odebiri, O.; Mutanga, O.; Odindi, J.; Peerbhay, K.; Dovey, S.; Ismail, R. Estimating soil organic carbon stocks under commercial forestry using topo-climate variables in KwaZulu-Natal, South Africa. S. Afr. J. Sci. 2020, 116, 1-8. [CrossRef]

51. Li, H.; Yang, W.; Lei, J.; She, J.; Zhou, X. Estimation of leaf water content from hyperspectral data of different plant species by using three new spectral absorption indices. PLOS ONE 2021, 16, e0249351.

52. El-Hendawy, S.E.; Al-Suhaibani, N.A.; Elsayed, S.; Hassan, W.M.; Dewir, Y.H.; Refay, Y.; Abdella, K.A. Potential of the existing and novel spectral reflectance indices for estimating the leaf water status and grain yield of spring wheat exposed to different irrigation rates. Agric. Water Manag. 2019, 217, 356-373. [CrossRef] 
53. Romero-Trigueros, C.; Nortes, P.A.; Alarcón, J.J.; Hunink, J.E.; Parra, M.; Contreras, S.; Droogers, P.; Nicolás, E. Effects of saline reclaimed waters and deficit irrigation on Citrus physiology assessed by UAV remote sensing. Agric. Water Manag. 2017, 183, 60-69. [CrossRef]

54. Mobasheri, M.R.; Fatemi, S.B. Leaf Equivalent Water Thickness assessment using reflectance at optimum wavelengths. Theor. Exp. Plant. Physiol. 2013, 25, 196-202. [CrossRef]

55. Riaño, D.; Vaughan, P.; Chuvieco, E.; Zarco-Tejada, P.J.; Ustin, S.L. Estimation of fuel moisture content by inversion of radiative transfer models to simulate equivalent water thickness and dry matter content: Analysis at leaf and canopy level. IEEE Trans. Geosci. Remote Sens. 2005, 43, 819-826. [CrossRef]

56. Jurdao, S.; Yebra, M.; Guerschman, J.P.; Chuvieco, E. Regional estimation of woodland moisture content by inverting Radiative Transfer Models. Remote Sens. Environ. 2013, 132, 59-70. [CrossRef]

57. García, M.; Chuvieco, E.; Nieto, H.; Aguado, I. Combining AVHRR and meteorological data for estimating live fuel moisture content. Remote Sens. Environ. 2008, 112, 3618-3627. [CrossRef]

58. Bar-Massada, A.; Sviri, A. Utilizing Vegetation and Environmental New Micro Spacecraft (VEN $\mu$ S) Data to Estimate Live Fuel Moisture Content in Israel's Mediterranean Ecosystems. IEEE J. Sel. Top. Appl. Earth Obs. Remote Sens. 2020, 13, $3204-3212$. [CrossRef]

59. Cao, Z.; Wang, Q. Retrieval of leaf fuel moisture contents from hyperspectral indices developed from dehydration experiments. Eur. J. Remote Sens. 2017, 50, 18-28. [CrossRef]

60. Sow, M.; Mbow, C.; Hély, C.; Fensholt, R.; Sambou, B. Estimation of herbaceous fuel moisture content using vegetation indices and land surface temperature from MODIS data. Remote Sens. 2013, 5, 2617-2638. [CrossRef]

61. Gerhards, M.; Schlerf, M.; Mallick, K.; Udelhoven, T. Challenges and future perspectives of multi-/Hyperspectral thermal infrared remote sensing for crop water-stress detection: A review. Remote Sens. 2019, 11, 1240. [CrossRef]

62. Mangus, D.L.; Sharda, A.; Zhang, N. Development and evaluation of thermal infrared imaging system for high spatial and temporal resolution crop water stress monitoring of corn within a greenhouse. Comput. Electron. Agric. 2016, 121, 149-159. [CrossRef]

63. Wang, R.; Cherkauer, K.; Bowling, L. Corn response to climate stress detected with satellite-based NDVI time series. Remote Sens. 2016, 8, 269. [CrossRef]

64. Lim, J.; Watanabe, N.; Yoshitoshi, R.; Kawamura, K. Simple in-field evaluation of moisture content in curing forage using normalized differece vegetation index (NDVI). Grassl. Sci. 2020, 66, 238-248. [CrossRef]

65. Ali, A.M.; Darvishzadeh, R.; Skidmore, A.K. Retrieval of specific leaf area from landsat-8 surface reflectance data using statistical and physical models. IEEE J. Sel. Top. Appl. Earth Obs. Remote Sens. 2017, 10, 3529-3536. [CrossRef]

66. Easterday, K.; Kislik, C.; Dawson, T.E.; Hogan, S.; Kelly, M. Remotely sensed water limitation in vegetation: Insights from an experiment with unmanned aerial vehicles (UAVs). Remote Sens. 2019, 11, 1853. [CrossRef]

67. Abdel-Rahman, E.M.; Ahmed, F.B.; Ismail, R. Random forest regression and spectral band selection for estimating sugarcane leaf nitrogen concentration using EO-1 Hyperion hyperspectral data. Int. J. Remote Sens. 2013, 34, 712-728. [CrossRef]

68. Zhu, Y.; Liu, K.; Liu, L.; Myint, S.W.; Wang, S.; Liu, H.; He, Z. Exploring the potential of worldview-2 red-edge band-based vegetation indices for estimation of mangrove leaf area index with machine learning algorithms. Remote Sens. 2017, 9, 1060. [CrossRef]

69. Liang, L.; Di, L.; Huang, T.; Wang, J.; Lin, L.; Wang, L.; Yang, M. Estimation of leaf nitrogen content in wheat using new hyperspectral indices and a random forest regression algorithm. Remote Sens. 2018, 10, 1940. [CrossRef]

70. Yuan, H.; Yang, G.; Li, C.; Wang, Y.; Liu, J.; Yu, H.; Feng, H.; Xu, B.; Zhao, X.; Yang, X. Retrieving soybean leaf area index from unmanned aerial vehicle hyperspectral remote sensing: Analysis of RF, ANN, and SVM regression models. Remote Sens. 2017, 9, 309. [CrossRef] 